\title{
THE CONCEPT AND CIVIL ASPECTS OF CULTURAL ACTIVITIES IN THE RUSSIAN FEDERATION
}

\author{
Maxim V. Sevostyanov \\ Volzhsky Branch of Volgograd State University, Volzhsky, Russian Federation
}

\begin{abstract}
Introduction: cultural activities are important in the lives of people at all stages of human development without exception. At present, culture as the basis of the activity under consideration is the subject of research in many humanities and other sciences. However, this activity also has private law properties that are in many cases identical to the system elements of civil law. The purpose of the publication is to identify these properties that affect the legal nature of cultural activities. Methods: the research is based on the system method, civilized techniques and the methods of interpretation, the methods of analysis and synthesis, and the comparative legal method. Results: the paper substantiates the author's view of cultural activity as a system of actions of the civil turnover participants aimed at creating, transforming, preserving, distributing and applying cultural values in the sphere of spiritual and material needs of a person. The studied activity is characterized by the subject elements of the civil law branch, which are manifested in the legal nature of the participants, the dynamics of ownership of the cultural objects, the contractual regulation of "cultural" relations, and the means of protecting cultural rights. Conclusions: in the course of the research, the author identifies the qualifying features of the cultural activity, united by the dynamics of cultural values in the context of improving the spiritual and material needs of people. The essence of civil law aspects inherent in cultural activities at the present stage of civil turnover development is determined and argued. The systemic nature of the fundamental, subject, object, real-law, contractual, intellectual, protective and other private-law aspects allows us to qualify cultural activities as a process of exercising civil rights. process.

Key words: culture, cultural activities, civil law, civil law aspects, civil law system, civil rights implementation

Citation. Sevostyanov M.V. The Concept and Civil Aspects of Cultural Activities in the Russian Federation. Legal Concept = Pravovaya paradigma, 2020, vol. 19, no. 4, pp. 110-115. (in Russian). DOI: https://doi.org/10.15688/lc.jvolsu.2020.4.14
\end{abstract}

\section{ПОНЯТИЕ И ГРАЖДАНСКО-ПРАВОВЫЕ АСПЕКТЫ КУЛЬТУРНОЙ ДЕЯТЕЛЬНОСТИ В РОССИЙСКОЙ ФЕДЕРАЦИИ}

\author{
Максим Владимирович Севостьянов \\ Волжский филиал Волгоградского государственного университета, г. Волжский, Российская Федерация
}

Введение: культурная деятельность имеет важное значение в жизни людей на всех без исключения этапах человеческого развития. В настоящее время культура как основа рассматриваемой деятельности является предметом исследований многих гуманитарных и иных наук. Вместе с тем эта деятельность обладает и частноправовыми свойствами, которые во многих случаях являются идентичными для системных элементов гражданского права. Выявление этих свойств, влияющих на правовую природу культурной деятельности, и является целью настоящей публикации. Методы: в основу проводимого исследования положены системный метод, цивилистические приемы и способы толкования, методы анализа и синтеза, сравнительно-правовой метод. Результаты: в статье обосновывается авторский взгляд на культурную деятельность как на систему действий участников гражданского оборота, направленных на создание, преобразование, сохранность, распространение и применение культурных ценностей в сфере духовно-материальных потребностей человека. Изучаемой деятельности присущи предметные элементы гражданско-правовой отрасли, проявляющиеся в пра- 
вовой природе ее участников, динамике права собственности на объекты культуры, договорном регулировании «культурных» отношений, средствах защиты культурных прав. Выводы: в процессе исследования выявляются квалифицирующие признаки культурной деятельности, объединенные динамикой культурных ценностей в контексте совершенствования духовных и материальных потребностей людей. Определяется и аргументируется сущность гражданско-правовых аспектов, присущих культурной деятельности на современном этапе развития гражданского оборота. Системный характер основополагающих, субъектных, объектных, вещно-правовых, договорных, интеллектуальных, охранительных и иных частноправовых аспектов позволяет квалифицировать культурную деятельность как процесс осуществления гражданских прав.

Ключевые слова: культура, культурная деятельность, гражданское право, гражданско-правовые аспекты, система гражданского права, процесс осуществления гражданских прав.

Цитирование. Севостьянов М. В. Понятие и гражданско-правовые аспекты культурной деятельности в Российской Федерации // Legal Concept = Правовая парадигма. - 2020. - T. 19, № 4. - C. 110-115. - DOI: https://doi.org/10.15688/lc.jvolsu.2020.4.14

\section{Введение}

В настоящее время культурная деятельность является неизбежным элементом общественных отношений. Несмотря на свою многогранность, эта деятельность в недостаточной степени изучена средствами цивилистической науки, что ограничивает ее осуществление в гражданском обороте. Цель проводимого исследования заключается в выявлении частноправовой природы культурной деятельности на современном этапе общественного развития. Для достижения цели необходимо решить две научные задачи: 1) сформулировать определение понятия «культурная деятельность»; 2) выявить и обосновать наличие ее гражданско-правовых аспектов.

В контексте методологии исследования следует обратить внимание на два фактора: во-первых, определения понятий воплощают в себе свойства окружающего нас мира и являются своеобразным взглядом на соответствующую правоприменительную область, отражающим в себе «познавательную силу диалектики» [1, с. 288]; во-вторых, ядром решения первой задачи будет выступать прием цивилистического толкования, представляющий собой анализ и последующий синтез результатов словесного и юридического толкования [2, с. 98, 127] термина «культурная деятельность».

\section{Определение понятия «культурная деятельность»}

В источниках российской лексикографии отмечается многоаспектный характер терми- на «культура». Например, в словаре С.И. Ожегова под ним понимается: 1) «совокупность производственных, общественных и духовных достижений людей»; 2) «разведение, выращивание какого-нибудь растения или животного»; 3) высокий уровень развития человеческих навыков. Дополняет указанные свойства и сущность слова «культурный», смысл которого заключается в наличии определенного результата деятельности людей, полученного в процессе «обработки», «возделывания», «выращивания» различных материальных и духовных объектов. Слово «деятельность» («деятельный») означает «занятие, труд, энергия....» $[5$, с. $167,216,314]$.

Таким образом, в словесном толковании «культурная деятельность - это проявление человеческой энергии посредством труда, работы, занятий, направленной на получение, сохранение, развитие, преобразование производственных и общественно-духовных потребностей людей на соответствующем этапе исторического развития».

В учебной литературе по культуре используется термин «социально-культурная деятельность», которая своими корнями уходит в сферы различных гуманитарных наук и по этой причине имеет комплексную природу [3, с. 5], отражающуюся на юридических свойствах изучаемого термина и его интерпретациях. Например, в ст. 44 Конституции РФ используется сочетание «культурная жизнь», в Гражданском кодексе РФ (далее - ГК) - «культурные ценности» (ч. 5 ст. 1), «культура» как образ жизни различных групп населения страны, в частности казачества (ч. 1 ст. 123.15), малочисленных народов (ст. 123.16) и др. 
Однако наиболееполное и буквальное юридическое толкование этого термина содержится в специализированных правовых источниках о культуре [6], где под культурной деятельностью понимается та деятельность, которая направлена на сохранение, создание, распространение и освоение культурных ценностей.

Для полноценного выявления сущности изучаемого вида деятельности необходимо определить содержание термина «культурные ценности», выступающего ее структурным элементом, а также составной частью различных гражданско-правовых норм, закрепленных, но не получивших в достаточной степени определенности в положениях ГК.

Проведенный анализ позволяет сделать вывод о том, что «культурные ценности» представляют собой своеобразный синтез материальных и нематериальных объектов человеческой жизнедеятельности, большинству из которых присущи признаки объектов гражданских прав. Например, к ним относятся результаты деятельности человека (художественные промыслы и ремесла, произведения искусства), вещи, имеющие историко-культурное значение, и др. [6].

Многогранность «культуры» отмечается и в современных научных правовых исследованиях, в которых рассматриваемое понятие объединяет в себе не только определенные ценности, но и различные верования, жизненный уклад, некоторые аспекты участия людей в жизни социума, отдельные области деятельности государства и муниципалитетов [7, с. 13].

Таким образом, на основании проведенного анализа и последующего синтеза можно дать авторское определение понятия «культурная деятельность». Под ней понимается «деятельность человека (граждан и/или организаций), преследующая своей целью создание (преобразование), сохранение, распространение и применение культурных ценностей в области материальных и духовных потребностей людей на определенном этапе развития общественных отношений».

\section{Гражданско-правовые аспекты культурной деятельности}

В лексическом значении термин «аспект» означает «точку зрения, взгляд на что-нибудь»
[5, с. 37]. В юридическом смысле под «культурными аспектами» понимается потенциал развития общественных, экономических, научных и иных направлений человеческой деятельности с точки зрения взаимного влияния полученных результатов на динамику культуры [6].

Таким образом, под гражданско-правовыми аспектами следует понимать влияние культурной деятельности на систему гражданского права с точки зрения динамики самой деятельности и составных элементов названной отрасли.

Исследователи культурной деятельности выделяют ее нормативную функцию, то есть способность влиять на формирование тех или иных правовых норм, ориентированных на определенные ценности как результаты культурного развития [3, с. 11]. В связи с этим фактором в статье анализу будут подвергаться положения ГК, в которых: 1) непосредственно содержатся отдельные, производные элементы от термина «культурная деятельность», поскольку в буквальном смысле искомый термин не используется в структуре кодекса («культура», «культурные ценности» и др.); 2) применяются термины и сочетания слов, напрямую не содержащие производные элементы от термина «культурная деятельность» или «культура», но по своему духовнонравственному и (или) смысловому значению тем или иным способом выражают соответствующие «культурные» аспекты; 3 ) имеются элементы государственно-муниципальной политики в области культуры, а также культурные компоненты субъектного состава участников гражданских отношений.

Основополагающий аспект базируется на основных началах гражданского законодательства, представленных в ст. 1 ГК. Например, граждане и организации обязаны действовать «добросовестно». И хотя по отношению к этому термину законодатель не применяет «культурные» элементы, в доктрине гражданского права отмечается «ярко выраженная» зависимость действия этого принципа с содержанием дошедших до нас памятников культуры, например «Псковской судной грамоты» [4, с. 32-33].

Другим составным элементом рассматриваемого аспекта является зависимость введения ограничений на динамику товаров и ус- 
луг от необходимости охраны «культурных ценностей» (ч. 5 ст. 1 ГК).

Субъектный аспект. Как известно, участниками гражданского оборота, или субъектами гражданского права, являются физические и юридические лица, определение правового положения которых является составной частью предмета исследуемой отрасли. Так, многие элементы рассматриваемого аспекта находят свое выражение в содержании правоспособности физического лица (ст. 18 ГК). Например, «культурные» составляющие просматриваются в имущественных отношениях граждан, в их праве на занятие предпринимательством, учреждении организаций, совершении сделок, выборе места жительства, реализации авторских и иных интеллектуальных прав.

Однако ярко выраженный культурный фактор содержится в праве гражданина иметь или не иметь «отчество» как составной элемент своего имени, во многом обусловленный национально-культурными обычаями.

Понятие «культура» в различных интерпретациях влияет и на правоспособность некоторых юридических лиц, выступая при этом составным элементом целей их учреждения и деятельности. Так, внесенные в реестр казачьи общества, общины коренных малочисленных народов России учреждаются с целью сохранения и развития своей культуры (ст. 123.15, 123.16 ГК).

Сущность объектного аспекта заключается в том, что составные элементы понятия «культура» и его производные представляют собой объекты гражданских прав в различных их интерпретациях (ст. 128 ГК). И хотя названная статья кодекса в буквальном смысле не содержит термина «культура», его составные элементы отчетливо просматриваются в фактическом содержании всех объектов. Например, «культурные ценности» представляют собой ничто иное как разновидность вещей во всем их многообразии, культурные компоненты могут входить в результаты работ, выступать составным элементом оказания услуг, интеллектуальной собственности и нематериальных благ.

Вещно-правовой аспект обусловлен свойствами культурных ценностей представлять собой объект материального мира (двор- цы культуры, музеи и др.), по отношению к которому и возникают соответствующие правомочия: право собственности или иные вещные права. Элементы культурной деятельности влияют на основания возникновения права собственности (например, клад как культурная ценность) и на ее прекращение (например, определенный ст. 240 ГК выкуп культурных ценностей), а также на последствия утери собственником недвижимости права пользования участком земли, в том случае если на этом участке находятся «памятники культуры» (ч. 2 ст. 272 ГК).

Договорный аспект проявляется в том, что договор является не только средством индивидуально-правового регулирования отношений, складывающихся в процессе осуществления культурной деятельности, но и средством защиты прав ее участников. При помощи договоров создаются новые культурные объекты материального мира, оказываются различные виды культурных услуг, осуществляется процесс передачи культурных ценностей и решаются иные «культурные» задачи. Поскольку договор представляет собой разновидность сделки и обязательства, то наряду со специальными нормами (гл. 30, 37, 39 ГК и др.) к договорным отношениям применяются общие положения кодекса о сделках, обязательствах и о договорах, что, безусловно, дополнительно подчеркивает гражданско-правовую сущность рассматриваемого аспекта.

Интеллектуальный аспект обусловлен правовой сущностью культурной деятельности, обладающей созидательным, творческим и иным подобным характером, проявляющимся в создании результатов интеллектуальной деятельности.

Охранительный аспект. Несмотря на то что базовые начала охраны государством объектов культурного наследия носят публично-правовой характер, охрана различных элементов культурной деятельности может осуществляться и при помощи предпринимательской охранной деятельности, имеющей ярко выраженную частноправовую природу. Например, в условиях распространения коронавирусной инфекции обеспечение пропускного и внутриобъктового режимов на объектах культуры (наличие масок, перчаток, соблюдение соци- 
альной дистанции и др.) может выступать средством защиты жизни и здоровья участников культурной деятельности и квалифицироваться как оказание охранных услуг [8, c. 128]. Подобные услуги могут быть востребованы и в случае защиты культурных объектов (зданий, концертных площадок и др.) от различного рода противоправных посягательств, а также в случае проведения массовых культурных мероприятий [9], которые стали неизбежным атрибутом государственных и профессиональных праздников.

\section{Выводы}

1. Культурная деятельность представляет собой целенаправленную деятельность граждан и организаций, имеющую направленность на созидание, сохранение, распространение и использование ценностей культуры в сфере материально-духовных потребностей людей, востребованных на соответствующих этапах общественного развития.

2. Культурная деятельность обладает ярко выраженными гражданско-правовыми аспектами, придающими этой деятельности частноправовой характер и позволяющими квалифицировать ее как процесс осуществления гражданских прав.

\section{СПИСОК ЛИТЕРАТУРЫ}

1. Алексеев, С. С. Общая теория права. В 2 т. Т. 1 / С. С. Алексеев. - М. : Юрид. лит., 1981.-361 с.

2. Васьковский, Е. В. Цивилистическая методология. Учение о толковании и применении гражданских законов / Е. В. Васьковский. - М. : АО «Центр ЮрИнфоР», 2002. - 580 с.

3. Кемерова, Т. А. Теория социально-культурной деятельности : учеб. пособие / Т. А. Кемерова. - Екатеринбург : Изд-во Урал. ун-та, 2019. - 103 с.

4. Коновалов, А. В. Принципы гражданского права: методологические и практические аспекты исследования : дис. ... .д-ра юрид. наук: 12.00.03 / Коновалов Александр Владимирович. -М., 2019. - 1161 с.

5. Ожегов, С. И. Словарь русского языка / С. И. Ожегов. - М. : Рус. яз., 1989. - 924 с.

6. Основы законодательства Российской Федерации о культуре : угв. ВС РФ 09.10.1992 № 3612-1 // Рос. газ. - 1992. - 17 нояб (№ 248).

7. Сазонникова, Е. В. Наука конституционного права России и концепт «культура»: вопросы теории и практики : автореф. дис. ....д-ра юрид. наук: 12.00.01 / Сазонникова Елена Викторовна. - М., 2012. $-46 \mathrm{c}$.

8. Шаронов, С. А. Понятие, правовая природа и классификация оказания охранных услуг как объекта гражданских прав в контексте осуществления предпринимательской охранной деятельности / С. А. Шаронов // Вестник Санкт-Петербургского университета МВД России. - 2018. - № 2. - С. 126-130.

9. Шаронов, С. А. Средства охраны прав участников концертных услуг / С. А. Шаронов // Исторические, философские, политические и юридические науки, культурология и искусствоведение. Вопросы теории и практики. - 2009. - № 3. C. 219-222.

\section{REFERENCES}

1. Alekseev S.S. Obshchaya teoriya prava. V 2 t. T. 1 [General Theory of Law. In 2 vols. Vol. 1]. Moscow, Yurid. lit, 1981.361 p.

2. Vask'kovskiy E.V. Tsivilisticheskaya metodologiya. Uchenie o tolkovanii i primenenii grazhdanskikh zakonov [Methodology of the Civil Law. The Doctrine of the Interpretation and Application of Civil Laws]. Moscow, JSC "Center Yurinfor", 2002. 580 p.

3. Kemerova T.A. Teoriya sotsial'no-kulturnoy deyatel'nosti: uchebnoe posobie [Theory of SocioCultural Activity: Textbook]. Yekaterinburg, Ed. Ural. Un-ta, 2019. $103 \mathrm{p}$.

4. Konovalov A.V. Printsipi grazhdanskogo prava: metologicheskie i prakticheskie aspecti issledovaniya: dis. ... d-ra yurid. nauk: 12.00.03 [Principles of Civil Law: Methodological and Practical Aspects of Research. Dr. jurid. sci. diss.]. Moscow, 2019. $1161 \mathrm{p}$.

5. Ozhegov S.I. Slovar' russkogo yazika [Dictionary of the Russian Language]. Moscow, Rus. yaz. Publ., 1989. 924 p.

6. Osnovi zakonodatel'stva Rossiyskoy Federatsii o kulture: utv. VS RF 09.10.1992 № 3612-1 [Fundamentals of the Legislation of the Russian Federation on Culture: Approved. Russian armed forces 09.10.1992 No. 3612-1]. Ros. Gaz, no. 248. 17.11.1992.

7. Sazonnikova E.V. Nauka konstitutsionnogo prava Rossii $i$ kontsept «kultura»: voprosi teorii $i$ prakiti: avtoref. dis. ... d-ra yurid. nauk: 12.00.01 [Science of Constitutional Law of Russia and the Concept of "Culture": Questions of theory and Practice. Dr. jurid. sci. abs. diss.]. Moscow, 2012. 46 p.

8. Sharonov S.A. Ponyatie, pravovaya priroda $i$ klassifikatsiya okazaniya okhrannikh uslug kak objecta grazhdanskikh prav v kontekste oshushyestvleniya 
M.В. Севостьянов. Понятие и гражданско-правовые аспекты культурной деятельности в Российской Федерации

predprinimatel'skoy okhrannoi deyatel'nosti [Concept, Legal Nature and Classification of Security Services as an Object of Civil Rights in the Context of Business Security Activities]. Vestnik SanktPeterburgskogo universiteta MVD Rossii, 2018, no. 2, pp. 126-130.
9. Sharonov S.A. Sredstva okhrani prav uchastnikov kontsertnikh uslug [Means of Protecting the Rights of Participants of Concert Services]. Istoricheskie, filosofskie, politicheskie i yuridicheskie nauki, kulturologiya i iskusstvovedenie. Voprosi teorii i praktiki, 2009, no. 3, pp. 219-222.

\section{Information About the Author}

Maxim V. Sevostyanov, Candidate of Sciences (Jurisprudence), Associate Professor, Director, Volzhsky Branch of Volgograd State University, 40 let Pobedy St, 11, 404133 Volzhsky, Russian Federation, Sev_mv@mail.ru, https://orcid.org/0000-0002-7248-9349

\section{Информация об авторе}

Максим Владимирович Севостьянов, кандидат юридических наук, доцент, директор Волжского филиала Волгоградского государственного университета, ул. 40 лет Победы, 11, 404133 г. Волжский, Российская Федерация, Sev_mv@mail.ru, https://orcid.org/0000-0002-7248-9349 